\title{
Developing of complex for hot plastic deformation modeling of steel type 20-30CrNiMoV for heavy forging
}

\author{
Vladimir Dub ${ }^{1, *}$, Alexandr Churyomov ${ }^{1}$, Igor Soloviev², Anton Popkov ${ }^{3}$ \\ ${ }^{1}$ The National University of Science and Technology MISiS, Russian Federation, \\ ${ }^{2}$ Ural Federal University named after the first President of Russia B.N.Yeltsin», Russian Federation, \\ ${ }^{3}$ United Heavy Machinery Plants, Russian Federation.
}

\begin{abstract}
Production of heavy forging of bars weighing more then 235 tons for such products as rotors made of steel type $20-30 \mathrm{CrNiMoV}$ is a critical independent work, failure to perform which entails high costs related to repeated production (in case of defective product) and untimely launch of production plants. One of the frequent causes of a defective product is the impossibility of ultrasonic testing in the barrel-gate zones on the rotor workpiece, which is due to the microstructure of the metal, namely the grain size. Determing the stages of deformation process wich causes such defects in structure is the main goal of this work.
\end{abstract}

\section{Formatting the title, authors and affiliations}

Decrease of defective products at all processing stages of metallurgical production is a priority task for researchers and production engineers. As is known, the grain size under deformation depends on the following parameters: degree of deformation $\varepsilon$, rate of deformation $\dot{\varepsilon} \mathrm{s}^{-1}$, temperature $T$. These physical parameters in turn are associated with the process parameters, such as tool operation time on the workpiece, $T$ of metal on the surface. Prediction of the structure change at different degrees of deformation and at a certain temperature is described on the basis of the theory of plastic deformation and can be modeled for specific technological processes $[1,2]$.

In turn, during deformation, recrystallization always occurs, which can be of three types: static, metadynamic and dynamic. One of the ways to optimize production processes at the stage of hot plastic deformation (HPD) of ingots is to model the structure using mathematical models and the finite elements method.

There are several phenomenological models that establish the connection between the stressed and deformed state of the medium [3-20]:

- Johnson-Cook model;

- Steinberg-Cochran-Guinan- Lund model;

- Zerilli-Armstrong model;

- Mechanical threshold stress model (MTS);

- Preston-Tonks-Wallace model.

At the present time in order to model the evolution of structure during the HPD process, the microstructure characteristics relationship models (volume fraction of recrystallized grains and grain size) with HPD parameters based on equations of Avrami-Kolmogorov type [3-8] are most widely used. They show a high predictive capability, but require a lot of experimental data in order to determine unknown constants.

Kinetics of dynamic recrystallization can be described by the following set of equations (1-4):

$$
\begin{gathered}
X_{D R X}=1-\exp \left[-\beta_{d} \cdot\left(\frac{\varepsilon-a_{10} \cdot \varepsilon_{p}}{\varepsilon_{0.5}}\right)^{k_{d}}\right] \\
\varepsilon_{0.5}=a_{5} \cdot d_{0}^{h_{5}} \cdot \varepsilon^{n_{5}} \cdot \dot{\varepsilon}^{m_{5}} \cdot \exp \left(\frac{Q_{5}}{R \cdot T}\right)+c_{5} \\
\varepsilon_{p}=a_{1} \cdot d_{0}^{n_{1}} \cdot \dot{\varepsilon}^{m_{1}} \exp \left(\frac{Q_{1}}{R \cdot T}\right)+c_{1} \\
\varepsilon_{c}=a_{2} \cdot \varepsilon_{p}
\end{gathered}
$$

where $d_{0}-$ initial grain size, $\mu \mathrm{m} ; \varepsilon_{0,5}-$ degree of deformation at $50 \%$ of the volume of recrystallized grains; $a_{1}, n_{1}, m_{1}, Q_{1}, c_{1}, a_{2}, a_{5}, h_{5}, n_{5}, m_{5}, Q_{5}, c_{5}, \beta_{d}, a_{10}, k_{d}-$ rheological parameters of the material, determined on the basis of the results of experimental studies.

To determine the size of dynamically recrystallized grains, the polynomial empirical equation with temperature dependence according to the Arrhenius law was used (5):

$$
d_{D R X}=a_{8} \cdot d_{0}^{h_{8}} \cdot \varepsilon^{n_{8}} \cdot \dot{\varepsilon}^{m_{8}} \cdot \exp \left(\frac{Q_{8}}{R \cdot T}\right)+c_{8}
$$

where $a_{8}, h_{8}, n_{8}, m_{8}, Q_{8}, c_{8}$ are the material rheological parameters determined on the basis of the results of experimental studies (if $d_{\mathrm{DRX}}>\mathrm{d}_{0}$, then $d_{\mathrm{DRX}}=d_{0}$ ).

Grain growth during the annealing of a non-deformed metal, or in the intervals between deformations, can be described by the following equation (6):

\footnotetext{
* Corresponding author: vladimir.dvchem@gmail.com
} 


$$
d_{g g}=\left[d_{0}^{m}+a_{9} t \exp \left(-\frac{Q_{9}}{R T}\right)\right]^{\frac{1}{m}}
$$

where $a_{9}, Q_{9}, m$ - are the material parameters determined on the basis of the results of experimental studies.

To determine the constant rheological parameters for steel type $20-30 \mathrm{CrNiMoV}$ included in the model, steel grade $26 \mathrm{HN} 3 \mathrm{M} 2 \mathrm{FA}$ was chosen and experimtens with the use of the Gleeble 3800 complex were carried out: Melting of $12 \mathrm{~kg}$ of ingots followed by forging into bars and annealing in order to obtain a structure with grains of different sizes $(50,200,1000 \mu \mathrm{m})$, simulating different zones of the ingot. An experiments matrix was developed to study the effect of the rate, degree and temperature of deformation on the size of austenite grain to determine the rheological parameters included in the phenological model.

Curves of deformation according to which the coefficients describing the kinetics of dynamic recrystallization for steel $26 \mathrm{HN} 3 \mathrm{M} 2 \mathrm{FA}$ were determined, are shown in Fig. 1. Kinetic parameters were determined using the method of minimizing the error between calculated and experimental values of the flow stress in the section of the deformation curve from the maximum value to the value corresponding to the steady-state stage of deformation.

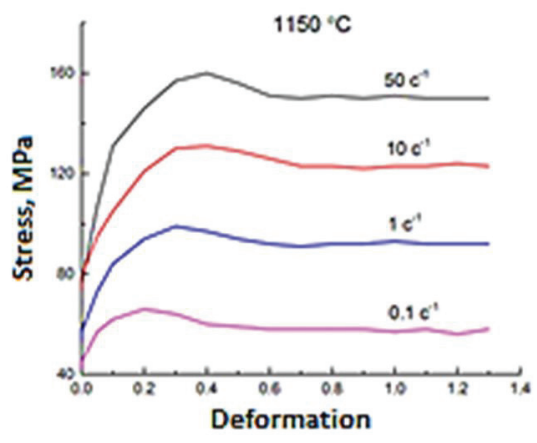

Fig. 1. Curves of deformation of dynamic recrystallization

Deformation curves for determination of dynamic recrystallization kinetics for 26HN3M2FA steel.

Unknown coefficients were determined on the basis of the results of microstructural studies of grain size after different deformation modes. Figure 2 shows typical microstructure of $26 \mathrm{HN} 3 \mathrm{M} 2 \mathrm{FA}$ steel with dynamically recrystallized structure.

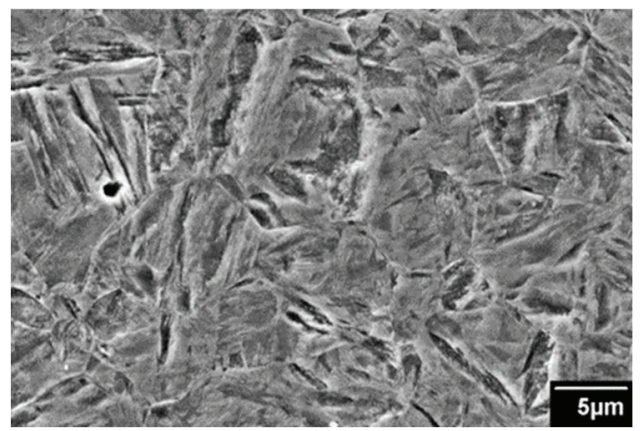

Fig. 2. Microstructure of the 26HN3M2FA steel (after deformation in the mode $\mathrm{T}=1150 \mathrm{C}^{\mathrm{o}}, \dot{\varepsilon}=50 \mathrm{c}-1, \varepsilon=1,3, \tau=0 \mathrm{c}$.
Comparison of experimental and calculated grain sizes for 26HN3M2FA steel is shown in Fig. 3. Average calculation error for the $26 \mathrm{HN} 3 \mathrm{M} 2 \mathrm{FA}$ steel was $5,2 \%$

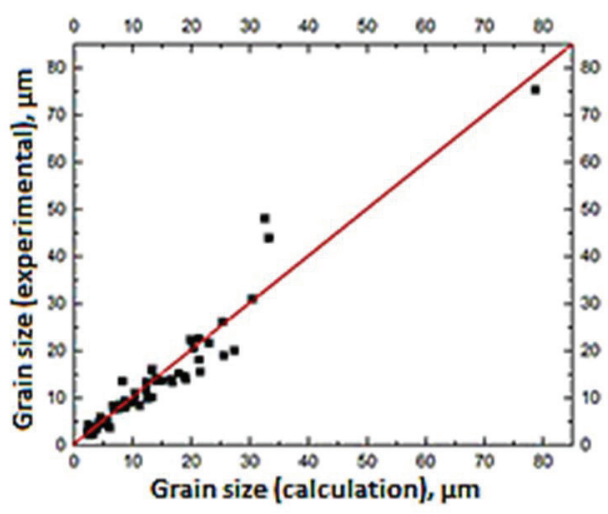

Fig. 3. Comparison of experimental and calculated grain sizes for $26 \mathrm{HN} 3 \mathrm{M} 2 \mathrm{FA}$ steel

\section{Comparison of calculated and experimental values of dynamically recrystallized grains for $26 \mathrm{HN} 3 \mathrm{M} 2 \mathrm{FA}$ steels}

More than 540 studies were carried out in order to determine the rheological parameters of $26 \mathrm{HN} 3 \mathrm{M} 2 \mathrm{FA}$ steel. As a result, a model that describes the deformation of 26XH3M2ФA steel was developed (7-8):

$$
\begin{gathered}
d_{D R X}=67352.5 \times d_{0}^{-0.051} \times \varepsilon^{-0,672} \times \dot{\varepsilon}^{-0,075} \times \exp \left(\frac{94000}{R \times T}\right) \\
d=d_{D R X} X_{D R X}+\left(1-X_{D R X}\right) d_{0}
\end{gathered}
$$

For modeling of the actual structure formation in the process of industrial HPD, obtained mathematical dependences (values of the coefficients) and rheological properties of materials are downloaded to the program that allows to calculate deformation processes using the finite element method. The model (7-8) is applied to determine grain in each element In the environment of finite element modeling, the initial geometry of the workpiece and deforming tool, the initial and boundary conditions, including the initial distribution of grain sizes are set. After that, the process conditions in the form of time dependencies of the workpiece position relative to the tool, its speed and the surface temperature of the workpiece are set.

Result of the calculation is the dependence of characteristics of the grain structure microstructure at the final moment of forming at each point of the workpiece on the HPD parameters (set by the corresponding time dependencies) (9):

$$
d=f\left(F_{G P D}(\tau), x_{i}, y_{i}, z_{i}\right)
$$


This model was used to study the distribution of grain for a rotor workpiece of bar with mass 235 tons in order to identify the least deformable zones.

Distribution in the initial ingot was modeled using the DeForm software package (40,000 items were studied).

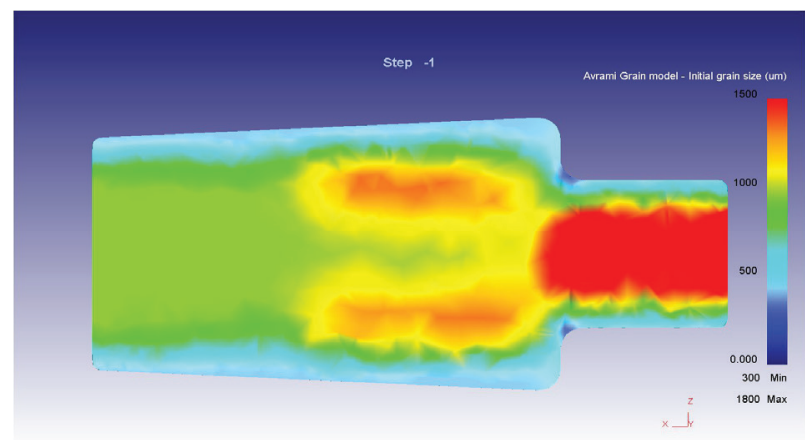

Fig. 4. Stage of hot deformation model of rotor forging

Further, the entire forging process was modeled taking into account the actual deformation conditions with measurement of geometric pattern, time and temperature. As a result, the most critical stage of forging the rotor workpiece was determined: deformation into circle.

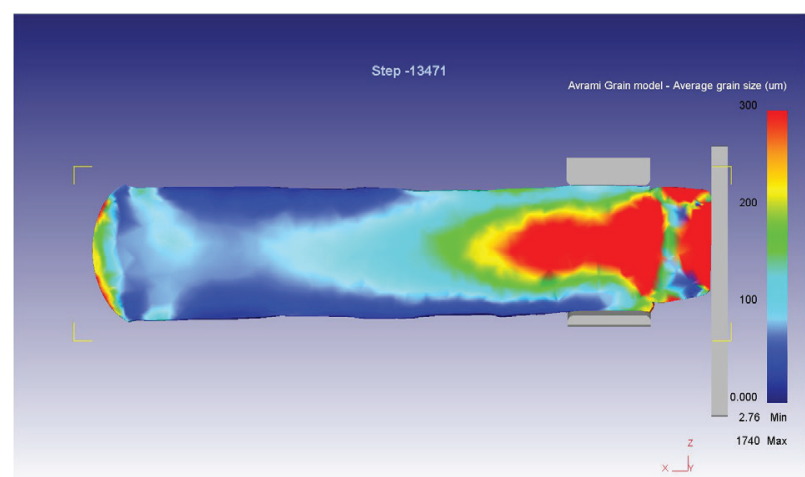

Fig. 5. Stage of hot deformation model of rotor forging

And the final distribution of grain after heating:

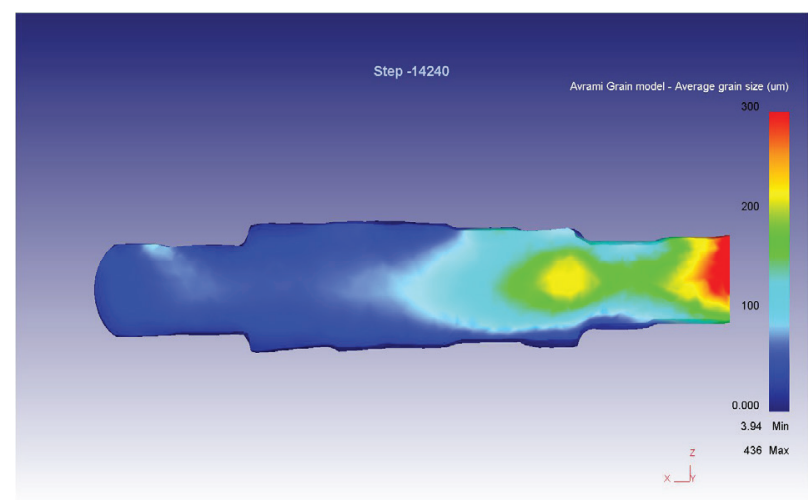

Fig. 6. Final stage of hot deformation model

It can be seen that the most problematic zone is «barrel-gate» with a grain size of more than $170 \mu \mathrm{m}$. These results are fundamental for predicting the technology of rotor deformation and adjusting the factory technology.

\section{Conclusion}

1. A phenomenological model describing the process of deformation for unique heavy forging (more than 230 tons) for power machine made of 20-30CrNiMoV type steel was developed.

2. On the basis of large array of experimental data, the unique constant parameters of a steel of the selected type, which determine the rheological properties of the material for the following thermal-deformation modes, were determined for the first time: $T=1230-900^{\circ} \mathrm{C}$; degree of deformation $0,17-1,3$; rate of deformation from 0.1 to $50 \mathrm{c}^{-1}$

3. Numerical modeling of the rotor workpiece forging process from an ingot of 235 tons was performed, and occurrence of critical zones with large grains (more than $170 \mu \mathrm{m})$ and the stage of formation of these zones was predicted for the first time.

This study was sponsored by the Ministry of Education and Science of the Russian Federation in frame of the Federal Targeted Program on Research and Development in Priority Areas of Development of the Russian Science and Technology Sector for 2014-2020 (Application ID: 2015-14-579-0173-366; unique ID of applied research: RFMEFI57815X0114).

\section{References}

1. R.W. Hertzberg Deformation and fracture mechanics of engineering materials, 786 (1996)

2. A.V. Dub, V. A. Durynin, V. S. Dub, [et al.] Proc. Sci.-Pract. Conf. Innovative Materials and Technologies for Nuclear and Other Types of Power Plants and Heavy Machinery Construction, Moscow, p. 8, (2011)

3. A.M. Elwazri, E. Essadiqi, S. Yue, ISIJ International, 44, N. 4, 744-752 (2004)

4. G. Shen, S.L Semiatin, and R. Shivpuri, Metallurgical and Materials Transactions A, 26A, 1795-1803, (1995)

5. A.J. Brand, K. Karhausen, R. Kopp., Materials Science and Technology. 12. 963-969 (1996).

6. X. Lei, J. Huang, X. Jin, S. Chen, X. Zhao, Materials Letters, 181, 240-243 (2016)

7. F. Yin, L. Hua, H. Mao, X. Han, D. Qian, R. Zhang, Materials \& Design, 55, 560-573 (2014)

8. Z. Jina, K. Lia, X. Wua, H. Dong, Proceedings 2S, 460-465 (2015)

9. S. Kim, Y. Lee, D. Lee, Y. Yoo., Mater. Sci. Eng. A. 355, 384-393 (2003)

10. K.R. Kinsman, H.I. Aaronson. Transformation and Hardenability in Steels, Climax Molybdenum Co., Ann. Arbour (Michigan, USA, 1967)

11. M.H. Jacobs, D.W. Pashley. The Mechanism of Phase Transformation in Crystalline Solids (Institute of Metals, London) Monograph no. 33, 43 p. (1969) 
12. Kwak D., Micro-Magnetic Examination of Thermal Fatigued Heat-Resistant Steels, PhD dissertation (2004)

13. M. Hojny, M. Głowacki and Z. Malinowski, High Temperature Materials and Processes, 28, 4, 245-252 (2009)

14. M. Głowacki and M. Hojny, Inverse Problems in Science and Engineering, 17, 2, 159-174 (2009)

15. P.J. Wray, Metall. Trans. A, 15A, 2041-2058 (1984)

16. Y. Saito et al., Kawasaki Steel Techn. Rep., No.9, 1221 (1984)

17. Y.W. Chen, R.L. Tobler, B.J. Fills, K.J. Coakley, NIST Technical Note 1500-6, Materials Reliability Series (1999)

18. N. Hatta, J. Kokado, S. Kikuchi, H. Takuda, Steel Res., 56, 575-582 (1985)

19. S. Sakai, T. Sakai, K. Takeishi, Trans ISIJ, 17, 718725 (1977)

20. D.C. Ludwigson, Metall. Trans., 2, 2825-2828 (1971) 